\title{
Liquid chromatography-tandem mass spectrometry (LC-MS) method for the assignment of enalapril and enalaprilat in human plasma
}

\author{
Hossein Danafar ${ }^{1,2^{*}}$, Mehrdad Hamidi ${ }^{3}$ \\ ${ }^{1}$ Pharmaceutical Nanotechnology Research Center, Zanjan University of Medical Sciences, Zanjan, Iran \\ ${ }^{2}$ Department of Pharmaceutics, School of Pharmacy, Zanjan University of Medical Sciences, Zanjan, Iran \\ ${ }^{3}$ Department of Pharmaceutics, School of Pharmacy, Zanjan University of Medical Sciences, Zanjan, Iran \\ Received: Oct 21, 2015, Revised: Nov 7, 2015, Accepted: Nov 11, 2015
}

\begin{abstract}
A rapid and sensitive liquid chromatography-tandem mass spectrometry (LC-MS) method was developed for the determination of enalapril and enalaprilat in human plasma. Detection of analytes was achieved by tandem mass spectrometry with electrospray ionization (ESI) interface in positive ion mode which was operated under the multiple-reaction monitoring mode. Sample pretreatment was involved in a onestep protein precipitation (PPT) with per chloric acid of plasma. The reconstituted samples were chromatographed on $\mathrm{C}_{18}$ column by pumping methanol: water: acid formic $74: 24: 2(\mathrm{v} / \mathrm{v})$ at a flow rate of $0.2 \mathrm{~mL} / \mathrm{min}$. Each plasma sample was chromatographed within $1.25 \mathrm{~min}$. The standard curves were found to be linear in the range of $0.1-20 \mathrm{ng} / \mathrm{mL}$ of enalapril and enalaprilat with mean correlation coefficient of $\geq 0.999$ for each analyte. The intra-day and inter-day precision and accuracy results were well within the acceptable limits. The limit of quantification (LOQ) was $0.1 \mathrm{ng} / \mathrm{ml}$ for enalapril and enalaprilat. The lower limit of detection (LOD) was $0.08 \mathrm{ng} / \mathrm{ml}$ for enalapril and enalaprilat.
\end{abstract}

Keywords: Enalapril, enalaprilat, LC-MS, human plasma

DOI: $10.18869 /$ acadpub.pbr.1.3.47

\section{Introduction}

Enalapril, N-((1S)-1-(ethoxycarbonyl)3-phenylpropyl)-1-proline (Fig.1A), belongs to the series of substituted $\mathrm{N}$ carboxymethyl dipeptides. Enalapril is a prodrug which is hydrolyzed after absorption forming the active angiotensin converting enzyme (ACE) inhibitor. The active form, enalaprilat (Fig. 1B), is a major metabolite of enalapril and has been shown to be effective in the treatment of hypertension and congestive heart failure without causing any significant side effects (1-4). Enalapril and enalaprilat are often determined simultaneously in biological fluids. Therefore, the simultaneous detection of enalapril and enalaprilat in human plasma is of prime importance for pharmacokinetic studies. Several analytical methods have been reported for determination of enalapril and enalaprilat in biological samples, including gas chromatography-mass spectrometry (GC-MS) (5), radioimmunoassay (RIA) (6) and enzyme kinetics (7). Recently, liquid chromatography-mass 


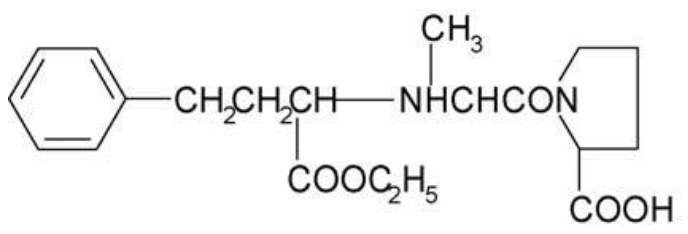

(A)

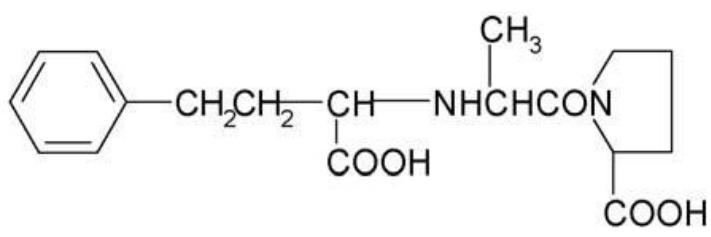

(B)

Figure 1 Chemical structures for (A) enalapril and (B) enalaprilat

spectrometry, LC-MS/MS $(8,9)$ and LC-MS $(10,11)$, was used in the determination of enalapril and enalaprilat. But the long analysis time (>3.5 min), large volume of plasma sample $(>0.5 \mathrm{~mL})$, or low extraction recovery may not meet the requirement for high throughput, speed and sensitivity in bio sample analysis.for quantitative analysis. Although these problems could be solved by using both low $\mathrm{pH}$ and high column temperature, $(12,13)$ these reported HPLC methods are not adequate forpharmacokinetic studies due to relatively high detection limits(1416).A simple method that can simultaneously determine enalapril and enalaprilat in human plasma was required.The pervious our work was described determination of ezetimibe by LC-MS method in human plasma (17). Our aim was to develop and validate a simple and rapid LC-MS method for the quantification of enalaprilat and enalapril in human plasma. The developed assay method was successfully applied to the determination of enalapril and enalaprilat in human plasma by LC-MS.

\section{Materials and methods}

Materials
Enalaprilat and enalapril maleate USP Reference standards (USPC Inc., Rockville, MD) were kindly donated by Dr Abidi Pharmaceutical Co. (Tehran, Iran). Other chemicals and solvents were from chemical lab or HPLC purity grades, whenever needed, and were purchased locally. Drug-free human plasma was provided by Iranian Blood Transfusion Organization after routine safety evaluations.

\section{Instrumentation and operating conditions}

Liquid chromatography

Liquid chromatography was performed using Agilent LC-1200 HPLC system consisting of an autosampler (Agilent, USA). The column was a Zorbax XDBODS C18 column $(2.1 \mathrm{~mm} \times 30 \mathrm{~mm}, 3.5$ $\mu \mathrm{m})$ and was operated at $25^{\circ} \mathrm{C}$. The mobile phase consisted of methanol: water: formic acid 74:24:2(v/v) was set at a flow rate of $0.2 \mathrm{ml} / \mathrm{min}$.

\section{Mass spectrometry}

Mass spectrometric detection was performed using Agilent LCMS-6410 quadrupole mass spectrometer with anelectrospray ionization (ESI) interface. The ESI source was set at positive ionization mode. The mass selective detector was used in the multiple reaction monitoring (MRM) 
mode for the highest possible selectivity and sensitivity. The MS operating conditions were optimized as follows: Ion spray voltage was set to $4000 \mathrm{~V}$, temperature of the ion transfer capillary was $250{ }^{\circ} \mathrm{C}$, Nebulizer gas (NEB) was 30psi, Dwell time per transition (ms) 200, gas flow $8 \mathrm{l} / \mathrm{min}$, Collision gas for enalapril and enalaprilat 20. Quantitative determinations were performed in multiple reactions monitoring scan mode using the following transitions: $\mathrm{m} / \mathrm{z} 377 \rightarrow 234$ for enalapril, $\mathrm{m} / \mathrm{z} 349 \rightarrow 206$ for enalaprilat. The quantification was performed via peak-area. Data acquisition and processing were accomplished using Agilent LC-MS solution Software forLCMS-6410 system.

\section{Standard preparation}

A stock solution of $0.2 \mathrm{mg} / \mathrm{ml}$ enalapril and enalaprilat in methanol were prepared, from which the concentrations of $0.1,0.5,0.1,2.5,5$ and $10 \mathrm{ng} / \mathrm{ml}$ for enalapril and enalaprilat were prepared by serially diluting this solution with the proper amount of mobile phase and plasma.

\section{Sample preparation and extraction procedure}

To $150 \mu \mathrm{L}$ calibration standards, QC samples, or plasma samples, $50 \mu \mathrm{L}$ per chloric acid was added. The mixtures were vortex mixed for $20 \mathrm{~s}$. After centrifugation at $15000 \times \mathrm{g}$ in an eppendorf microcentrifuge tubes for 20 min. An aliquot of $10 \mu \mathrm{L}$ was injected into the LC-MS system.

\section{Method validation}

Assay specificity

In order to evaluate the matrix effect on the ionization of analytes, three

different concentration levels of enalapril and enalaprilat $(0.10,10.0$ and $20.0 \mathrm{ng} / \mathrm{ml}$ ) were prepared in the drugfree blank plasma and the samples were processed, as described, and injected to LC-MS. The same concentrations were prepared in mobile phase instead of plasma and analyzed for drug concentration using the same procedure. A comparison of the matrix effects of the two variants was made as an indicator of the method specificity.

\section{Linearity}

The plasma samples with a series of known concentrations were analyzed in three separate runs and, in each case, the linear regression analysis was carried out on known concentrations of enalapril and enalaprilat against the corresponding peak heights and, then, the regression coefficient (r), slope, and $y$-intercept of the resulting calibration curves were determined.

\section{Within-run variations}

In one run, three samples with concentrations of $0.1,10$, and $20 \mathrm{ng} / \mathrm{ml}$ (from high, middle, and low regions of the standard curve) for enalapril and enalaprilat were prepared in triplicate and analyzed by developed LC-Mass method. Then, the coefficient of variations (CV\%) of the corresponding determined concentrations were calculated in each case.

\section{Between-run variations}

On three different runs, samples from upper, intermediate, and lower concentration regions used for construction of standard curve (the same as within-run variations test) were prepared and analyzed by LC-Mas 
method. Then, the corresponding CV\% values were calculated.

\section{Absolute recovery (accuracy)}

For each sample tested for within- and between-run variations, the absolute recovery of the method was determined as the percent ratio of the measured concentration (determined using standard curve) to the corresponding nominal added concentration.

\section{Extraction recovery and matrix effect}

The extraction efficiency of enalapril and enalaprilat was determined by analyzing six replicates of plasma samples at three QC concentration levels of $0.1,10$, and $20 \mathrm{ng} / \mathrm{ml}$ (from low, middle, and high regions of the standard curve) for enalapril and enalaprilat were prepared in triplicate and analyzed by developed LC-Mass method. The recovery was calculated by comparing the peak areas of the enalapril and enalaprilat added into blank plasma and extracted using the PPT procedure with those obtained from the two compounds spiked into post-extraction supernatant at three QC concentration levels. The matrix effect was measured by comparing the peak response of sample spiked postextraction (A) with that of pure standard solution containing equivalent amounts of the two compounds (B). The ratio $(\mathrm{A} / \mathrm{B} \times 100) \%$ was used to evaluate the matrix effect.

\section{Limits of detection and quantitation}

Limit of detection (LOD) of the method was determined as the lowest enalapril and enalaprilat concentration producing a signal-to-noise $(\mathrm{S} / \mathrm{N})$ ratio of about 3 , 4 respectively. Limit of quantitation (LOQ) was determined as the lowest enalapril and enalaprilat concentration capable of being quantitated with enough accuracy and precision.

\section{Stability}

Freeze and thaw stability

Three concentration levels of QC plasma samples were stored at the storage temperature $\left(-20^{\circ} \mathrm{C}\right)$ for $24 \mathrm{~h}$ and thawed unassisted at room temperature. When completely thawed, the samples were refrozen for $24 \mathrm{~h}$ under the same conditions. The freezethaw cycle were repeated twice, then the samples were tested after three freeze ($20{ }^{\circ} \mathrm{C}$ )-thaw (room temperature) cycles.

\section{Short-term temperature stability}

Three concentration levels of QC plasma samples were kept at room temperature for a period that exceeded the routine preparation time of samples (around $6 \mathrm{~h}$ ).

\section{Long-term stability}

Three concentration levels of QC plasma samples kept at low temperature $\left(-20^{\circ} \mathrm{C}\right)$ were studied for a period of 4 weeks.

\section{Post-preparative stability}

The auto sampler stability was conducted reanalyzing extracted QC samples kept under the auto sampler conditions $\left(4^{\circ} \mathrm{C}\right)$ for $12 \mathrm{~h}$.

\section{Selectivity}

The selectivity was evaluated by comparing the chromatograms of six different batches of blank plasma obtained from six subjects with those of corresponding standard plasma samples spiked with enalapril and enalaprilat (5 $\mathrm{ng} / \mathrm{ml}$ ) and plasma sample after oral dose of enalapril maleate. 


\section{Results and discussion}

\section{Sample preparation}

Liquid-liquid extraction (LLE) and solid-phase extraction (SPE) are techniques often used in the preparation of biological samples for their ability to improve the sensitivity and robustness of assay. SPE was employed in the extract of enalapril and enalaprilat from plasma samples (9) in which the recoveries were not reported. LLE was also reported in the literature (8) for the sample pretreatment of enalapril and enalaprilat in human plasma, the recoveries were only around $65 \%$ and $24 \%$ for the two compounds, respectively. The significantly different extraction recoveries for enalapril and enalaprilat are due to the difference in hydrophobic character between them. The recoveries of enalapril and enalaprilat with protein precipitation were increased to compare with LLE (10), but the sensitivity was not satisfactory without a concentrate procedure. In the present method, a protein precipitation method was adopted which provided high recovery for both analytes. Under the optimal LC-MS conditions, the obtained sensitivity was higher than that reported in the literature (10). Therefore no further concentration procedure was needed; the sample preparation procedure was simplified. Both methanol and $\mathrm{HClO} 4$ could be taken as the protein precipitant. They provided equivalent extraction recovery. $\mathrm{HClO} 4$ was chosen as the precipitant for its better compatibility with mobile phase.

\section{LC-MS condition optimization}

LC-MS operation parameters were carefully optimized for determination of enalapril and enalaprilat. The mass spectrometer was tuned in both positive and negative ionization modes with ESI for both enalapril and enalaprilat containing secondary amino and carboxy groups. Both signal intensity and ratio of signal to noise obtained in positive ionization mode were much greater than those in negative ionization mode. Parameters such as desolation temperature, ESI source temperature, capillary and cone voltage, flow rate of desolation gas and cone gas were optimized to obtain highest intensity of protonated molecules of the two compounds. The product ion scan spectra showed high abundance fragment ions at m/z 234 and 206 for enalapril and enalaprilat, respectively. The collision gas pressure and collision energy of collision-induced decomposition CI were optimized for maximum response of the fragmentation of the two compounds. Multiple reaction monitoring (MRM) using the precursor $\rightarrow$ product ion transition of $\mathrm{m} / \mathrm{z} 377 \rightarrow \mathrm{m} / \mathrm{z} \mathrm{234,} \mathrm{m/z349} \rightarrow \mathrm{m} / \mathrm{z}$ 206 was employed for quantification of enalapril and enalaprilat, respectively. The multiple-reaction monitoring mode $(\mathrm{MRM})(+) \quad$ chromatograms extracted from supplemented plasma are depicted in Fig.2 as shown, the retention times of enalapril and enalaprilat were $1.23 \mathrm{~min}$. The total HPLC-MS analysis time was 1.25 min per sample.

\section{Method validation}

Assay specificity

As it is clearly evident from the typical chromatograms of the developed method shown in Fig.2, there are no discernible interferences between the matrix factors and the analyte. This, in turn, ensures obtaining reliable results from the method for determination of 
(A)

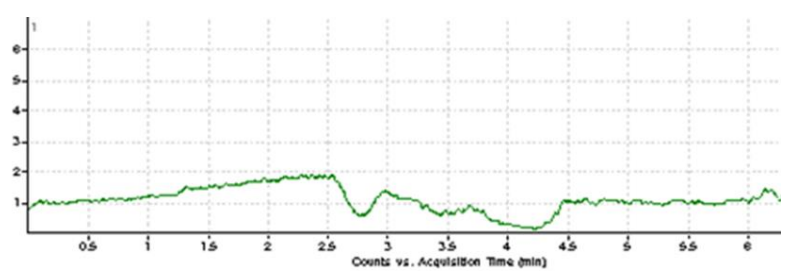

(B)

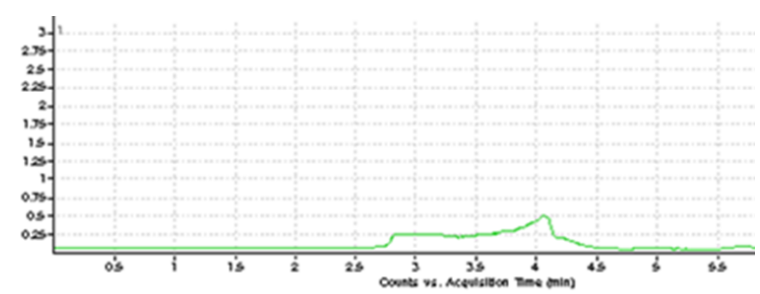

(C)

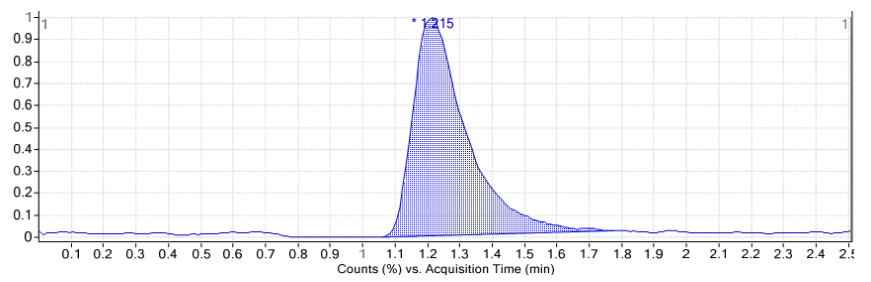

(D)

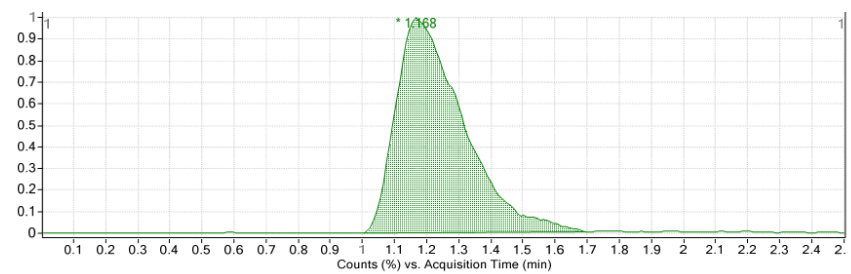

(E)

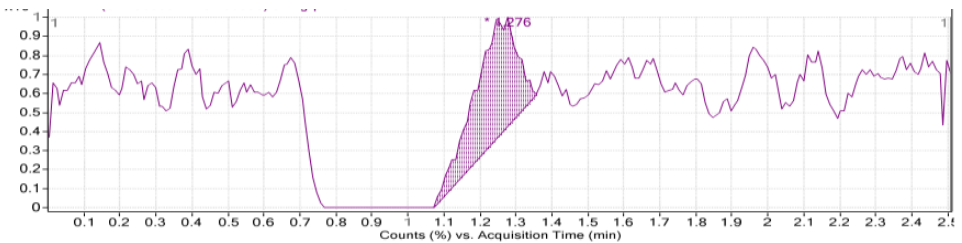

(F)

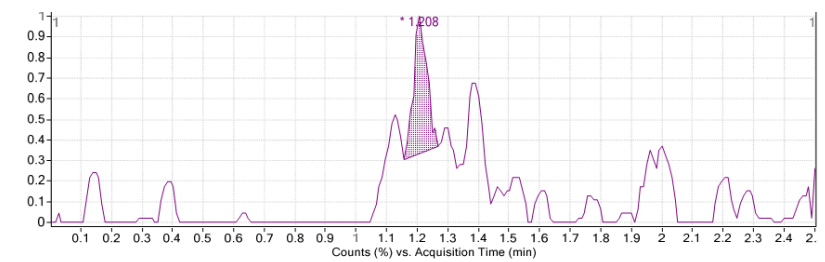

(G)

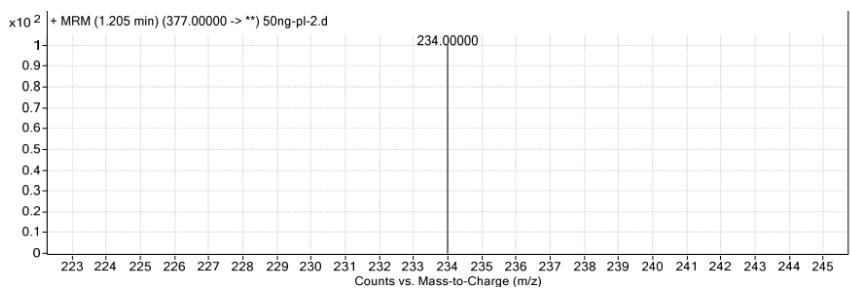

Figure 2 The MRM (+) chromatograms of enalapril and enalaprilate .(A): Blank plasma of enalaprilat ,(B): Blank plasma of enalapril ,(C): supplemented plasma (concentration of enalapril $=5 \mathrm{ng} / \mathrm{ml}$ ), (D): supplemented plasma (concentration of enalaprilat $=5 \mathrm{ng} / \mathrm{ml}),(\mathrm{E})$ : LOQ (concentration of enalapril $=0.1 \mathrm{ng} / \mathrm{ml})$. (F) LOQ (concentration of enalaprilat $=0.1 \mathrm{ng} / \mathrm{ml}),(\mathrm{G})$ : the mass spectrum MRM of enalapril 
biological concentrations of enalapril and enalaprilat.

\section{Linearity and $L O Q$}

The method produced linear responses throughout the enalapril and enalaprilat. Concentration range of $0.1-10 \mathrm{ng} / \mathrm{ml}$ for enalapril and enalaprilat, which is suitable for intended purposes. A typical linear regression equation of the method was: $\mathrm{y}=2867 \mathrm{x}+1132$, for enalapril and $\mathrm{y}=456.2 \mathrm{x}+121$,for enalaprilat, with $\mathrm{x}$ and $\mathrm{y}$ representing concentration (in $\mathrm{ng} / \mathrm{ml}$ ) and peak height (in arbitrary units), respectively, and the regression coefficient (r) of 0.999. The LLOQ for the two compounds was $0.1 \mathrm{ng} / \mathrm{ml}$ in plasma corresponded to an on-column sensitivity of $1.06 \mathrm{pg}$, which was lower than those reported in literature $(5-9,11)$. The lower limit of detection for enalapril and enalaprilat were 0.08 $\mathrm{ng} / \mathrm{ml}$. Figures $2 \mathrm{E}, \mathrm{F}$ show the chromatogram of an extracted sample that contained (LOQ) of enalapril and enalaprilat. Figures $2 \mathrm{C}$, D show the chromatogram ofan extracted sample that contained of enalapril and enalaprilat with concentrations of $5 \mathrm{ng} / \mathrm{ml}$. Figure $2 \mathrm{G}$ show the precursor $\rightarrow$ product ion transition of $\mathrm{m} / \mathrm{z} 377 \rightarrow \mathrm{m} / \mathrm{z} 234$ of enalapril.

\section{Within-run variations and accuracy}

The within-run variations of the developed LC-Mass method as well as the corresponding absolute recoveries are shown in tables 1 and 2.

\section{Between-run variations and accuracy}

The between-run variations of the developed LC-Mass method as well as the corresponding absolute recoveries are shown in table 3 and 4 .

\section{Extraction recovery}

The extraction recovery determined for enalapril and enalapril at were shown to be consistent, precise and reproducible. Data were shown below in Table 5,6. The extraction recoveries from QC samples at low, middle and high concentrations were $95.17 \pm 4.4 \%$, $94.08 \pm 4.33 \%, \quad 96.47 \pm 6.46 \%$ for enalapril and $93.62 \pm 3.18 \%$, $95.34 \pm 6.93 \%, \quad 94.71 \pm 7.53 \%$ for enalaprilat, respectively. The recoveries were much higher than those reported in the literature $(8,10)$ for the two compounds. In terms of matrix effect, all the ratios defined as in Section 2 were between $85 \%$ and $115 \%$. No significant matrix effect for enalapril and enalaprilat was observed indicating that no co-eluting substance could influence the ionization of the analytes.

\section{Stability}

Tables 7 and 8 summarizes the freeze and thaw stability, short-term stability, long-term stability and post-preparative stability data enalapril and enalaprilat. All the results showed the stability behavior during these tests and there were no stability related problems during the samples routine analysis for thepharmacokinetic, bioavailability or bioequivalence studies. The stability of working solutions was tested at room temperature for $6 \mathrm{~h}$. Based on the results obtained, these working solutions were stable within $6 \mathrm{~h}$.

\section{Selectivity}

Selectivity was determined by comparing the chromatograms of six different batches of blank human plasma with the corresponding spiked plasma. As shown in Fig.2, no interference from endogenous substance was observed at the retention time of enalapril, and enlaprilat. 
Table 1 Within-run variations and accuracy of the LC-Mass method for quantitation of enalapril $(\mathrm{n}=3)$

\begin{tabular}{cccccc}
\hline $\begin{array}{c}\text { Nominal Added } \\
\text { concentration } \\
(\mathrm{ng} / \mathrm{ml})\end{array}$ & $\begin{array}{c}\text { Sample } \\
\text { number }\end{array}$ & $\begin{array}{c}\text { Measured } \\
\text { concentration } \\
(\mathrm{ng} / \mathrm{ml})\end{array}$ & Mean (SD) & RSD\% & $\begin{array}{c}\text { Accuracy } \\
(\%)\end{array}$ \\
\hline 0.1 & 1 & 0.099 & 0.098 & 3.55 & 98 \\
& 2 & 0.095 & $(0.0035)$ & & \\
\hline 10 & 3 & 0.102 & & & \\
& 1 & 9.65 & $9.92(0.24)$ & 2.4 & 99.2 \\
\hline 20 & 2 & 10.12 & & & \\
\hline & 1 & 10.01 & & & \\
\hline
\end{tabular}

Table 2 Within-run variations and accuracy of the LC-Mass method for quantitation of enalaprilat $(n=3)$

\begin{tabular}{cccccc}
\hline $\begin{array}{c}\text { Nominal Added } \\
\text { concentration } \\
(\mathrm{ng} / \mathrm{ml})\end{array}$ & $\begin{array}{c}\text { Sample } \\
\text { number }\end{array}$ & $\begin{array}{c}\text { Measured } \\
\text { concentration } \\
\text { (ng/ml) }\end{array}$ & Mean (SD) & RSD\% & $\begin{array}{c}\text { Accuracy } \\
(\%)\end{array}$ \\
\hline 0.1 & 1 & 0.098 & $0.1(0.012)$ & 11.47 & 100 \\
& 2 & 0.12 & & & \\
\hline 10 & 3 & 0.10 & & & \\
& 1 & 10.25 & $10.04(0.18)$ & 1.86 & 100.4 \\
\hline 20 & 3 & 9.89 & & & \\
\hline & 1 & 9.98 & & & \\
\hline
\end{tabular}


Table 3 Between-run variations and accuracy of the LC-Mass method for quantitation of Enalapril $(\mathrm{n}=3)$

\begin{tabular}{cccccc}
\hline $\begin{array}{c}\text { Nominal Added } \\
\text { concentration } \\
(\mathrm{ng} / \mathrm{ml})\end{array}$ & $\begin{array}{c}\text { Run } \\
\text { number }\end{array}$ & $\begin{array}{c}\text { Measured } \\
\text { concentration } \\
(\mathrm{ng} / \mathrm{ml})\end{array}$ & $\begin{array}{c}\text { Mean } \\
(\mathrm{SD})\end{array}$ & RSD\% & $\begin{array}{c}\text { Accuracy } \\
(\%)\end{array}$ \\
\hline 0.1 & 1 & 0.098 & 0.097 & 2.67 & 97 \\
& 2 & 0.102 & $(0.002)$ & & \\
\hline 10 & 3 & 0.097 & & & \\
& 1 & 10.57 & 10.18 & 3.32 & 101.18 \\
\hline 20 & 2 & 9.96 & $(0.33)$ & & \\
\hline & 1 & 10.01 & & & \\
\hline & 2 & 20.1 & 19.99 & 1.92 & 99.95 \\
& 3 & 19.57 & $(0.38)$ & & \\
\hline
\end{tabular}

Table 4 Between-run variations and accuracy of the LC-Mass method for quantitation of enalaprilat $(\mathrm{n}=3)$

\begin{tabular}{cccccc}
\hline $\begin{array}{c}\text { Nominal Added } \\
\text { concentration } \\
(\mathrm{ng} / \mathrm{ml})\end{array}$ & $\begin{array}{c}\text { Run } \\
\text { number }\end{array}$ & $\begin{array}{c}\text { Measured } \\
\text { concentration } \\
(\mathrm{ng} / \mathrm{ml})\end{array}$ & $\begin{array}{c}\text { Mean } \\
(\mathrm{SD})\end{array}$ & RSD\% & $\begin{array}{c}\text { Accuracy } \\
(\%)\end{array}$ \\
\hline 0.1 & 1 & 0.098 & 0.10 & 10.98 & 100 \\
& 2 & 0.102 & $(0.011)$ & & \\
\hline 10 & 3 & 0.12 & & & \\
& 2 & 10.31 & 10.01 & 2.56 & 100.1 \\
& 3 & 9.87 & $(0.26)$ & & \\
\hline 20 & 1 & 9.86 & & & \\
& 2 & 20.38 & 20.07 & 1.29 & 100.35 \\
& 3 & 19.98 & $(0.26)$ & & \\
\hline
\end{tabular}


Table 5 Relative recovery of enalapril by the LC-Mass method $(\mathrm{n}=3)$

\begin{tabular}{ccccc}
\hline $\begin{array}{c}\text { Nominal Added } \\
\text { concentration (ng/ml) }\end{array}$ & $\begin{array}{c}\text { Sample } \\
\text { number }\end{array}$ & Recovery (\%) & Mean (SD) & $\begin{array}{c}\text { RSD } \\
\%\end{array}$ \\
\hline 0.1 & 1 & 90.11 & $95.17(4.40)$ & 4.62 \\
& 2 & 97.32 & & \\
\hline 10 & 3 & 98.09 & & \\
& 1 & 97.20 & $94.08(4.33)$ & 4.59 \\
& 2 & 89.14 & & \\
\hline 20 & 3 & 95.89 & & \\
& 2 & 101.00 & & \\
& 3 & 99.34 & & \\
\end{tabular}

Table 6 Relative recovery of enalaprilat by the LC-Mass method $(n=3)$

\begin{tabular}{ccccc}
\hline $\begin{array}{c}\text { Nominal Added } \\
\text { concentration } \\
(\mathrm{ng} / \mathrm{ml})\end{array}$ & $\begin{array}{c}\text { Sample } \\
\text { number }\end{array}$ & $\begin{array}{c}\text { Recovery } \\
(\%)\end{array}$ & Mean (SD) & $\begin{array}{c}\text { RSD } \\
\%\end{array}$ \\
\hline 0.1 & 1 & 93.19 & $93.62(3.18)$ & 3.4 \\
& 2 & 90.67 & & \\
\hline 10 & 3 & 97.00 & $95.34(6.93)$ & 7.27 \\
& 1 & 89.09 & & \\
\hline 20 & 2 & 94.14 & $94.71(7.53)$ & 7.95 \\
& 3 & 102.81 & & \\
\hline
\end{tabular}


Table 7 Data showing stability of enalapril in human plasma at different QC levels $(n=5)$

\begin{tabular}{cccc}
\hline & $0.1(\mathrm{ng} / \mathrm{ml})$ & $10(\mathrm{ng} / \mathrm{ml})$ & $20(\mathrm{ng} / \mathrm{ml})$ \\
\hline Short-term stability & 91.18 & 91.2 & 90.18 \\
\hline Freeze and thaw stability & 92.3 & 94.01 & 95.21 \\
\hline Long-term stability & 96.15 & 93.65 & 95.58 \\
\hline Post-preparative stability & 97.14 & 91.87 & 91.14 \\
\hline
\end{tabular}

Table 8 Data showing stability of enalaprilat in human plasma at different $\mathrm{QC}$ levels $(\mathrm{n}=5)$

\begin{tabular}{cccc}
\hline & $0.1(\mathrm{ng} / \mathrm{ml})$ & $10(\mathrm{ng} / \mathrm{ml})$ & $20(\mathrm{ng} / \mathrm{ml})$ \\
\hline Short-term stability & 95.57 & 90.65 & 95.65 \\
\hline Freeze and thaw stability & 96.56 & 93.25 & 94.73 \\
\hline Long-term stability & 93.61 & 94.52 & 95.94 \\
\hline Post-preparative stability & 91.65 & 92.31 & 91.57 \\
\hline
\end{tabular}

\section{Conclusion}

A sensitive, selective, accurate and precise LC-MS method with selected ion monitoring by single quadrupole massspectrometer with ESI interface in positive ion mode with multiplereaction monitoring mode was developed and validated for determination of enalapril and enalaprilat in human plasma. The reported method offers several advantages such as a rapid and simple extraction scheme, and a short chromatographic run time, which makes the method suitable for the analysis of large sample batches resulting from study of enalapril and enalaprilat in human plasma.

\section{Acknowledgement}

The authors would like to thank the authority of the Faculty of Pharmacy, Zanjan University of Medical Sciences, for their support.

\section{Conflict of Interest}

The authors declared no conflict of interest. 


\section{References}

1. Tabacova SA, Kimmel CA. Enalapril: pharmacokinetic/ dynamic inferences for comparative developmental toxicity. Reprod Toxicol 2001;15:467-78.

2. Smith DH. Treatment of hypertension with an angiotensin II-receptor antagonist compared with an angiotensin-converting enzyme inhibitor: a review of clinical studies of telmisartan and enalapril. Clin Ther 2002;24:1484-501.

3. Niopas I, Daftsios AC, Nikolaidis N. Bioequivalence study of two brands of enalapril tablets after single oral administration to healthy volunteers. Int $\mathbf{J}$ Clin Pharmacol Ther 2003;41:226-30.

4. Tabacova SA, Kimmel CA. Optimization of processing parameters for the mycelial growth. Int J Cariol 2005;25:237-2.

5. Shioya H, Shimojo M, Kawahara Y. Determination of enalapril and its active metabolite enalaprilat in plasma and urine by gas chromatography/mass spectrometry. Biomed Chromatogr 1992;6:59-62.

6. Worland PJ, Jarrott B, Radioimmunoassay for the quantitation of lisinopril and enaprilat. J Pharm Sci 1986;75:512-6.

7. Thongnopnua P, Poeaknapo C. Liquid chromatographic separation and UV determination of certain antihypertensive agents. J Pharm Biomed Anal 2005;37:763-9.

8. Gu Q, Chen XY, Zhong DF, Wang YW. Quantification of enalapril in human plasma by liquid chromatography -tandem mass spectrometry. J Chromatogr B 2004;813: 337-42.

9. Lee J, Son J, Lee M, Lee KT, Kim DH. Simultaneous quantitation of enalapril and enalaprilat in human plasma by $96-$ well solid-phase extraction and liquid chromatography/tandem mass spectrometry. Rapid Commun Mass Spectrom 2003;17:1157-62.

10. Liu C, Yang LH, Ding L, Bian XJ. Simultaneous quantitation of enalapril and enalaprilat in human plasma by liquid chromatography/tandem mass spectrometry. Chin J Clin Pharm 2006;15:34-7.
11. Yoon KH, Kim W, Park J, Kim H. Quantification of enalapril in human plasma by liquid chromatography -tandem mass spectrometry. J Bull Korean Chem Soc 2004;25:878-80.

12. Trabelsi H, Bouabdallah S, Sabbah S, Raouafi F, Bouzouita K. Study of the cistrans isomerization of enalapril by reversed-phase liquid chromatography. J Chromatogr A 2000;871:189-99.

13. Kocijan A, Grahek R, Kocjan D, Kralj LZ. Simultaneous quantitation of enalapril and enalaprilat in human plasma by 96 -well solid-phase extraction and liquid chromatography/tandem mass spectrometry. J Chromatogr B 2001;755:229-39.

14. Walily AFME, Belal SF, Heaba EA, Kersh AE. Simultaneous determination of enalapril maleate and hydrochlorothiazide by first-derivative ultraviolet spectrophotometry and high-performance liquid chromatography. J Pharm Biomed Anal 1995;13:851-6.

15. Qin XZ, Joe DM, Dominic PI. Determination and rotamer separation enalapril maleate by capillary electrophoresis. J Chromatogr A 1995; 707:245-55

16. Tajerzadeh H, Hamidi M. A simple HPLC method for quantitation of enalaprilat. $\mathrm{J}$ Pharm Biomed Anal 2001;24:675-880.

17. Danafar H, Hamidi M. A Rapid and Sensitive LC-MS Method for Determination of Ezetimibe Concentration in Human Plasma: Application to a Bioequivalence Study. Chromatographia 2013;76:1667-75. 